\title{
REDES SOCIAIS, ATOR SOCIAL E TRANSFORMAÇÕES CORRENTES: UMA TENTATIVA DE APROXIMAÇÃO
}

\section{SOCIAL NETWORKS, SOCIAL ACTOR AND TRANSFORMATIONS CHAINS: AN ATTEMPT AT APPROACH}

\author{
Recebido: 03/02/2015 - Aprovado: 05/04/2015 - Publicado: 15/05/2015 \\ Processo de Avaliação: Double Blind Review
}

\section{Ronaldo Raemy Rangel ${ }^{l}$}

Doutor em Desenvolvimento Econômico - UNICAMP - Universidade Estadual de Campinas Professor da Escola Paulista de Negócios e coordenador do Pós-MBA em Inteligência Empresarial da Fundação Getulio Vargas - FGV

\section{Fabiana Pereira Pinheiro}

Mestre em Administração - PUC -SP- Pontifícia Universidade Católica de São Paulo

\section{RESUMO:}

O texto pretende associar como elemento explicativo da constituição de Redes Sociais, por um lado as exigências derivadas das transformações recentes pelas quais o mundo e a economia vem passando e, por outro, a mudança forma de agir e da racionalidade dos atores sociais. Para tanto, vale- se de autores consagrados sobre o campo de estudo, elencados por meio da revisão sistemática da literatura existente que é uma técnica qualitativa que se vale do levantamento dos trabalhos relevantes sobre um tema para identificar e selecionar conclusões ou teses argumentativas. Os textos apresentados em Encontros Nacionais da Associação Nacional de Pós-Graduação e Pesquisa em Administração (ANPAD) foram a base de tal escolha. A estes associam-se outros textos, essencialmente egressos da ciência política, visando dar forma explicativa as transformações sociais e políticas.

Palavras-Chave: Redes Sociais; Transformações Políticas; Atores Sociais.

\begin{abstract}
:
The text aims to bind as explanatory element of Social networking, on the one hand the requirements derived from the recent transformations in which the world and the economy has been going through and changing way of acting and the rationality of social actors. To this end, Valley of established authors about the field of study, listed through the systematic review of existing literature that is a qualitative technique to survey of relevant jobs Valley on a topic to identify and select conclusions or argumentative thesis. The texts presented at national meetings of the National Association of graduate studies and research in management (ANPAD) were the basis of such a choice. These are other texts, essentially from political science, graduating aimed at shaping social and political transformations explanatory.
\end{abstract}

Keywords: Social Networks; Political Changes; Social Actors.

\footnotetext{
${ }^{1}$ Autor para correspondência: Fundação Getúlio Vargas - FGV-IDE

Rua Maringá, 1.200 - bairro Vl. Nova, Francisco Beltrão - PR, 85605-010. osmarinagarcia@ hotmail.com
} 


\section{INTRODUÇÃO:}

Atualmente, diversos estudiosos vêm se esforçando na análise e interpretação das Redes Sociais, visto sua relevância frente ao esgotamento das relações sociais de produção típicas da regulação de Estados intervencionistas o que, acelerado pela Globalização e pelos avanços na Tecnologia da Informação, alteram o ambiente organizacional, social e político, exigindo a construção de novas bases de cooperação para os atores sociais.

Entende-se que as Redes Sociais emergem, neste contexto, por um lado dado as necessidades de adaptação da sociedade frente as transformações pelas quais a economia, a regulação da estrutura produtiva e, portanto, as próprias relações sociais vêm passando, exigindo novos arranjos e alianças entre os atores para ampliar, ou ao menos, manter seus direitos e conquistas. Por outro lado, a alteração na forma de interagir (e agir) dos atores implica em uma mudança de comportamento, que vem acompanhada pela construção de uma nova racionalidade.

Tradicionais cientistas políticos brasileiros dão base para a interpretação das transformações sociais, enquanto autores sobre o tema Redes, elencados por meio da revisão sistemática da literatura existente, identificados pelo número de citações encontradas em textos apresentados em Encontros Nacionais da Associação Nacional de Pós-Graduação e Pesquisa em Administração (ANPAD) ${ }^{2}$, apontam teses explicativas para o papel da Redes Sociais neste ambiente de mudanças e, em certo sentido, de incertezas.

\section{O CONTEXTO DAS TRANSFORMAÇÕES:}

Na década de 1970, o cientista político Hélio Jaguaribe publicou o livro "Introdução ao desenvolvimento social" (JAGUARIBE, 1979). Embora importante à época, a obra não obteve grande repercussão, salvo em algumas classes de cursos de sociologia e ou de ciência políticas, pois, em algum sentido, possibilitava um contraponto à emergente corrente da dialética do subdesenvolvimento na América Latina, cujo referencial teórico baseava-se no livro de Paul Baran "A Economia Política do Desenvolvimento" (BARAN,1985), publicado originalmente em 1957.

Resumidamente, Jaguaribe (1979) sustenta sua obra em dois argumentos centrais. O primeiro reside na assertiva de que o desenvolvimento é um fenômeno social global, que envolve aspectos culturais, sociais e econômicos. Atesta assim, por consequência, que não há país que possa ser considerado desenvolvido se não o for, simultaneamente, em termos culturais, sociais e econômicos.

\footnotetext{
${ }^{2}$ Tal escolha se deveu à credibilidade da entidade na área da Administração de Empresas, tendo sido facilitada pelo fato de que o banco de dados da ANPAD é organizado, atualizado e todos os trabalhos estão disponíveis em formato digital, com condições sistemáticas de busca. O critério para identificação de autores foi o número de citações em trabalhos aprovados para serem apresentados nos EnANPAD.
} 
O segundo argumento chave é que o desenvolvimento raramente ocorre de forma espontânea, devendo, portanto, ser induzido. Evidentemente, tal indução poderia ser promovida indistintamente por aspectos culturais, sociais ou econômicos. Entretanto, afirma o autor, é pelo viés econômico que mais facilmente é alcançado.

Nesse sentido, certo é que inúmeras tentativas de induzir o desenvolvimento pelo esforço de coordenação econômica se propagaram no mundo ao longo dos anos 1970 e 1980. Entretanto, todas as buscas testadas: a do Capitalismo de Estado ${ }^{3}$ (escolha brasileira e de diversos países sul-americanos), o ideário do Capitalismo Organizado ${ }^{4}$ (Japão), ou mesmo, os modelos de cunho mais liberal como os adotados por alguns países europeus (Irlanda e Espanha) que se esmeraram em tentar prover o desenvolvimento por meio de um processo erguido na tese de crescer com distribuição, independente de certos e inegáveis méritos, todos fracassaram em seu intuito de criar o almejado desenvolvimento social global.

De toda sorte, o final desse período é marcado pela chamada crise do Padrão Fordista, quando houve a passagem para um regime de acumulação inteiramente novo, associado a um sistema de regulamentação política e social bem distinto dos até então conhecidos.

Não resta dúvida que, em tal contexto, uma série de novas experiências nos domínios das organizações, da vida social e da esfera política gerariam um clima de incerteza, já que padrões, corretos ou errados, porém até ali claramente estabelecidos, passaram a ganhar contornos heterogêneos em relação à capacidade de intervenção dos Estados Nacionais sobre as transformações correntes, quer de cunho econômico, social, tecnológico e mesmo ideológico.

\section{AS TRANSFORMAÇÕES E OS ATORES:}

O citado fenômeno de transformação acabou por estimular a ação (ou reação) de atores sociais que se organizaram em instâncias intermediárias de poder, usualmente chamadas de Terceiro Setor, ou por intermédio de Redes Sociais de diversas naturezas, sendo claro que tal esforço não se deu de forma linear, ou seja, não se estabeleceu nos mesmos ritmos e velocidades e, em algum sentido, nem tão pouco expressaram uma mesma tendência de ação, comportamento ou poder de mediação.

Não por outro motivo, nos anos recentes, diversos estudiosos têm-se debruçado sob a análise e interpretação das redes sociais, visto sua relevância frente ao esgarçamento das tradicionais relações sociais de produção típicas da regulação do Welfare State ${ }^{5}$ que,

\footnotetext{
${ }^{3}$ Estado é mais importante ator da economia a ponto de influenciar os resultados econômicos do país, não só direcionando a iniciativa privada, como atuando como produtor de bens e serviços, normalmente, por via de empresas estatais. Segundo Otavio Ianni, a ingerência do setor público assume nuances de "privatização do Estado". Ver a respeito: IANNI, 1981.

${ }^{4}$ A expressão entende uma situação econômica de cooperação entre a instância estatal e a iniciativa privada, por meio da criação de mecanismos reguladores que possibilitem um crescimento econômico continuado e a diminuição das crises inerentes ao próprio capitalismo. Ver a respeito: BURLAMAQUI, 1993.

${ }^{5}$ Conceitualmente o Welfare State (Estado do Bem Estar Social) tem a missão de fomentar o ciclo básico de investimento, emprego e demanda. Trata-se, portanto, de um Estado intervencionista a quem cabe o papel de criar as condições para o investimento, o que, por seu turno, fará com que se criem postos de trabalho e,
} 
acelerado pela Globalização e pelos avanços na Tecnologia da Informação, atuam como vetores que impactam o ambiente organizacional, social e político, exigindo o desenvolvimento de novas habilidades e a busca permanente de novas bases de cooperação. Contudo, o preceito básico de que o desenvolvimento é um fenômeno social global não deixa de se manter presente, muito embora, seu elemento indutor possa estar migrando dos aspectos econômicos para os sociais.

Cabe destacar que a ruptura ou esvaziamento do padrão de acumulação fordista destituiu a lógica da padronização produtiva voltada para mercados homogêneos e de demanda estável, assim como a necessidade do alargamento dos ciclos de vida dos produtos e, principalmente, depôs o consumo de massa como foco e paradigma de gestão.

Entretanto, eram essas questões que garantiam a estabilidade do modo de produção, permitindo o estabelecimento de uma estrutura ou de um modelo econômico centrado em uma espécie de equilíbrio geral paretiano, sendo claro que a teoria econômica ensina que podem coexistir Ótimos de Pareto distintos e, principalmente, que uma situação "ótima" se refere, de fato, a comparações entre situações, o que não traz, necessariamente em si, aspectos benéficos ou aceitáveis em termos sociais (PARETO, 1996).

De toda sorte, tal situação permitia aos atores sociais uma relação, de certa forma, serena com o mundo. Relação essa baseada no princípio do comportamento econômicoracional e na crença de que agir racionalmente é agir de forma socialmente aceitável.

Vale apresentar a argumentação de Habermas (1987) que descreve quatro tipos de ações dos indivíduos, sendo uma delas, a chamada ação teleológica, pela qual o ator articula meios a fins. Dito de outra forma, é o modo pelo qual o indivíduo aceita como dada a determinação dos fins em si mesmos. É, portanto, uma questão em que o ator resolve ou toma decisões supondo estar agindo solidariamente, já que considera, ou julga ser, o seu interesse próprio (e as restrições existentes a eles) como coletivos.

Como se percebe, a teoria do comportamento econômico-racional desconsidera as limitações para que os agentes realizem cálculos sobre ganhos e perdas, pois se pressupõem a existência de informações amplas ou "perfeitas" acerca das possibilidades de escolha, o que não seria crível obter. De toda maneira, Pareto (1996) afirma que uma situação econômica será ótima quando não for mais possível melhorar a situação de um agente sem degradar a situação de qualquer outro. Como se percebe, as relações sociais, as instâncias públicas e mesmo o meio político pouco interferem no "ótimo" proposto que é, em verdade, um jogo no qual um jogador só obtém ganho com o prejuízo de outro, sendo que não ganhar é não provocar perda.

Contudo, no artigo "Ação Econômica e Estrutura Social: O problema da imersão", Mark Granovetter (2009) alerta que:

consequentemente, com que se aumente o poder de compra e a procura de bens, por parte dos trabalhadores. Isto fará com que haja novamente a possibilidade de investimentos, provocando uma sucessiva continuidade deste ciclo. 
Grande parte da tradição utilitarista, inclusive a economia clássica e a neoclássica, presume um comportamento racional e de interesse pessoal minimamente afetado pelas relações sociais, invocando, assim, um estado idealizado. [...]. No outro extremo reside o que chamo de proposta da imersão (embeddedness): o argumento de que os comportamentos e as instituições a serem analisados são tão compelidos pelas contínuas relações sociais que interpretá-los como sendo elementos independentes representa um grave mal-entendido (GRANOVETTER, 2009, p. 33).

Em verdade, o autor alerta que as instituições influenciam a vida social, criando costumes e hábitos nos atores que estabelecem um sistema de normas que será seguido independente de critérios precípuos de escolhas de comportamento racional. Indo além, Granovetter afirma: [...] o fato de as regras interiorizadas de comportamento serem sociais em sua origem não diferencia decisivamente esse argumento da posição utilitarista[...]" (GRANOVETTER, 2009, p. 37).

Dessa forma, a imersão não altera o sentido de racionalidade individual, apenas lhe dá senso de conduta social ou, se preferível, socializada, na qual a ação humana é afetada pelas relações sociais onde o ator está imerso sem, contudo, retirar o caráter atomizado das decisões ou ações, mesmo quando tais ações envolvem grupos (maiores ou menores) de indivíduos.

\section{AS REDES:}

Assim, o argumento da imersão cria dispositivos institucionais de representatividade (via de regra, legítimos), mas não altera o papel das relações interpessoais concretas. São estas relações, que ao fim e ao cabo, estabelecerão as estruturas das Redes.

Note-se, que pelo exposto, existirá sempre certa e inegável dualidade na atuação das Redes Sociais, pois em alguns momentos atuarão de maneira utilitarista na busca de resultados ou vantagens decorrentes de interesses próprios. Em outros - e dicotomicamente -

agirão na busca de interesse estritamente coletivos, estabelecidos por valores ou necessidades acordadas por seus integrantes.

Deste modo, o conceito de Rede, ainda nesse contexto, ganha dimensão ampla, sendo que é tratado de forma diversa pelas diferentes áreas do conhecimento. Fleury e Ouverney (2007) oferecem grande contribuição para sua compreensão ao apresentar o conceito de rede derivado de autores das diferentes áreas. Na psicologia social, por exemplo, o termo rede tem sido utilizado para definir o universo relacional de um indivíduo, ou seja, o conjunto de relações e estruturas de apoio sócio afetivo de cada um. Já na sociologia, o estudo das redes diz respeito aos movimentos sociais que integram atores diversos, articulando o local e o global, o particular e o universal. Na administração de empresas, a rede é definida como a combinação de pessoas, tecnologia e conhecimento que substitui a corporação hierarquizada do modelo fordista, baseado em trabalho, capital e gerenciamento. $\mathrm{Na}$ gestão intergovernamental, rede é vista como um tópico oriundo da junção das disciplinas de política e administração, ou como um modelo estratégico de gestão de políticas, ou ainda como um 
novo modelo de governança que envolve os níveis local e global. Há ainda o conceito de redes políticas, entendendo-as como um conjunto de relações relativamente estáveis, de natureza não hierárquica e independente, que vinculam uma variedade de atores que compartilham interesses comuns em relação a uma política e que trocam entre si recursos para perseguir esses interesses comuns, admitindo que a cooperação seja a melhor maneira de alcançar metas compartilhadas.

Como se percebe, as redes estão incorporadas na vasta malha das relações sociais, quer de produção, da política, ou, meramente, de interesses sociais. As Redes, então, atuam (com maior ou menor intensidade) em todas as dimensões do conceito de desenvolvimento como um fenômeno social global. Não há, portanto, como descartar a importância de seu papel para o desenvolvimento social.

\begin{abstract}
De uma perspectiva sistêmica, o conceito de rede tende a aparecer como chave cognitiva privilegiada para compreender mudanças de grande magnitude que vêm ocorrendo nas esferas política e econômica da sociedade. Na esfera econômica, a rede parece constituir uma resposta aos desafios colocados às empresas. [...]. Na esfera política, a rede parece constituir uma resposta [...] à erosão da soberania do Estado contemporâneo. [...]. Por sua vez, da perspectiva dos movimentos sociais, a rede tende a aparecer como uma ferramenta capaz de construir novas formas de agregação, de interesses e reivindicação de demandas [...] destinadas, prioritariamente, a auxiliar na construção de uma sociedade solidária (MINHOTO; MARTINS, 2001, p. 89-90).
\end{abstract}

No livro "A gramática política do Brasil: clientelismo, corporativismos e insulamento burocrático" NUNES, 2010), o autor demonstra a evolução da estrutura do Estado como sendo efeito direto das práticas de poder hegemônicas da sociedade brasileira em cada um de seus estágios. De forma resumida, o Estado clientelista tem sua origem no resquício das estruturas familiares agrário exportadoras do fim do Império e no coronelismo que emerge nos primórdios da República. Por seu turno, o corporativismo estatal surge das demandas pela universalidade de procedimentos da burguesia urbana que pontificaram os anos 1930 e 1940 . O insulamento é consequência do Estado Tecnocrático estabelecido nas conturbadas décadas de 1960 e 1970.

Aceitando-se a lógica proposta pelo autor, devemos reconhecer que a ascendência das Redes Sociais, hoje, incorpora à "gramática política" uma estrutura de Estado que, simultaneamente, responde à fragmentação do WelfareState e ao insucesso das propostas neoliberais decorrentes do Consenso de Washington ${ }^{6}$. Com efeito, as Redes Sociais

\footnotetext{
${ }^{6} \mathrm{O}$ Consenso de Washington corresponde à construção de uma matriz neoliberal apresentada aos países da América Latina em novembro de 1989, para a qual a adesão era exigida em troca do refinanciamento das dívidas daqueles países. Essencialmente, o Consenso abrangia 10 pontos a serem cumpridos pelos países: Disciplina Fiscal, Priorizarão dos Gastos Públicos, Reforma Tributária; Liberalização Financeira, Regime Cambial, Liberalização Comercial, Investimentos Diretos Estrangeiro, Privatização das Estatais, Desregulamentação e Constituição da Nova Lei de Propriedade Intelectual. Tais tópicos, quando implementados, acabaram por provocar uma drástica redução do Estado e, em algum sentido, corrosões no próprio conceito de Nação, além de terem maximizado a abertura à importação de bens e serviços e potencializado a entrada de capitais de risco. Ver a respeito: NOGUEIRA BATISTA, 1995.
} 
possibilitam o estabelecimento de um paradigma de Estado "logístico" que percebe a existência de uma sociedade madura, avançada e com instâncias populares de representação legítima, para a qual transfere responsabilidades, num modelo decisório de inserção autônoma, onde os atores sociais transitam de um quadro de dependência estrutural à interdependência real (RANGEL, 2012).

Transportando tal premissa para outras esferas das relações sociais, inclusive para aquelas típicas de mercado, verifica-se que um dos resultados das transformações correntes no mundo empresarial é que, gradualmente, as alianças passam a ter mais relevância que as hierarquias tradicionais. Para alguns autores há o reconhecimento de que nenhuma organização se complementa em si mesma, criando uma nova condição de ações articuladas na busca de complementaridade. Segundo Minhoto e Martins (2001):

[...] a troca constitui a estrutura, a trama, o tecido da rede. De um lado essa arquitetura se expressa por um banco de oferta de recursos e competências disponibilizados formal ou informalmente por instituições, organizações ou pessoas; de outro, ela se expressa por um banco de demandas sociais e dos propósitos componentes da rede (MINHOTO; MARTINS, 2001, p. 87).

A expansão de alianças estratégicas, entendida como um tipo de Rede, não se limita às relações Inter firmas. Pelo contrário, estende-se a uma gama de laços ou de conexões sociais, tecnológicas, políticas e culturais, sendo que, de toda forma, as alianças tendem a estar menos centradas na estrutura de interação entre os atores que delas participam e mais no conteúdo ou vantagens absolutas obtidas nessas interações.

Retomando o conceito de imersão, evidencia-se que as alianças serão fortemente influenciadas pelo contexto social em que se estabelecerem. Assim, as Rede, devem ser estruturadas de modo a reduzir o risco de ações motivadas (ou induzidas) pela racionalidade utilitarista, dado que, de acordo com Lopes e Baldi (2009):

\footnotetext{
As redes, como outras formas estruturais, resultam de pressões ambientais e da ação humana, elas podem ser formas de transformação da realidade organizacional e social - deslocando o poder do centro para a periferia e recolocando a dimensão política como dimensão central - e também formas de reproduzir a ordem estabelecida, dando ares de modernidade, de flexibilidade, de eficiência, de justificação técnica para interesses de grupos nas disputas de poder (LOPES; BALDI, 2009, p. 1029).
}

Entretanto, as Redes são uma alternativa para administrar políticas, projetos e implicações complexas que envolvam multiplicidade de atores interessados, sejam da esfera pública ou privada, estejam territorialmente no local ou dele afastados, demandem benefícios econômicos ou apenas participação cidadã. 


\section{CONSIDERAÇÕES FINAIS:}

Sumariamente, observa-se pela revisão da literatura realizada, que as redes são instâncias de inserção autônoma dos atores envolvidos, que cumprem a missão de superar ou de suprir a inexistência do aparato de intervenção governamental, construindo vínculos e compromissos coletivos, dos quais, inexoravelmente, a dimensão econômica fará parte, mas que, porém, está de fato essencialmente subordinada à dimensão ética ou cultural e política.

A análise de redes objetiva estabelecer o conjunto de relações que os indivíduos mantêm por via de suas interações concretas com os demais membros da rede e que influenciam as escolhas, orientações e comportamentos de seus integrantes.

Entretanto, tal situação presume o desenvolvimento de um sistema de governança nada trivial da Rede, sendo necessário que se pactue a confiança e o comprometimento de seus integrantes, assim como estruturas que minimizem a possibilidade de comportamento oportunista, possibilitando que os atores sociais sejam protagonistas, simultaneamente, do seu próprio desenvolvimento e do desenvolvimento social global.

\section{REFERÊNCIAS:}

BARAN, P. A Economia Política do Desenvolvimento. Rio de Janeiro: Zahar Editores. 1985.

BURLAMAQUI, L. Reestruturação Capitalista e Capitalismo Organizado. In: Revista Ange (Associação Nacional de Cursos de Graduação em Economia), Rio de Janeiro, v. 5, p. 9-32, 1993.

FLEURY, S.; OVERNEY, A. Gestão de Redes: a estratégia de regionalização da política de saúde. Rio de Janeiro. FGV, 2007.

GRANOVETTER, M. Ação Econômica e Estrutura Social: O problema da imersão. In: MARTES, A.C. (org.). Redes e Sociologia Econômica. São Carlos: EdUFSCar, 2009.

HABERMAS, J. Teoría de laAcción Comunicativa: Racionalidad de laacción y racionalización social. Madrid: Taurus, 1987.

IANNI, O. A Ditadura do Grande Capital. Rio de Janeiro: Civilização Brasileira, 1981

JAGUARIBE, H. Introdução ao desenvolvimento social. Rio de Janeiro: Paz e Terra, 1979.

LOPES, F.; BALDI, M. Redes como perspectiva de análise e como estrutura de governança: uma análise das diferentes contribuições. Revista de Administração Pública. Rio de Janeiro 43(5), set/out, 2009. 
MINHOTO, L.; MARTINS, C. As redes e o desenvolvimento social. Cadernos FUNDAP, n 22, 2001, pg 89-90

NOGUEIRA BATISTA, P. O Consenso de Washington: A Visão Neoliberal dos Problemas Latino-Americanos. In: Caderno Dívida Externa, v. 6. São Paulo: 1995.

NUNES, E. A gramática política do Brasil: clientelismo, corporativismos e insulamento burocrático. Rio de Janeiro: Garamond, 2010.

PARETO, V. Manual da Economia Política, Coleção os Economistas. São Paulo: Nova Cultura, 1996.

RANGEL, R. O Novo Perfildo Mercado de Consumo Brasileiro: Um Ensaio Sobre a Capacidade de Indução do Estado. RevistaCientífica Hermes, v. 7, p. 63-73, 2012. 